\title{
A Simplified Predictive Current Control for Matrix Converters with Reduced Common-mode Voltage
}

\author{
Thanh-Luan Nguyen, Hong-Hee Lee, Tae-Won Chun \\ School of Electrical Engineering, University of Ulsan, Korea \\ luanlik4@gmail.com; hhlee@mail.ulsan.ar.kr; twchun@mail.ulsan.ar.kr
}

\begin{abstract}
Predictive current control (PCC) is an effective method to control matrix converters (MCs) due to its advantages such as simplicity, fast dynamic response, and flexibility to control different variables. However, the high amount of calculations for the PCC is an obstacle for its real application. To overcome this problem, this paper proposes a simplified PCC method for MCs by utilizing the sector distribution. In addition, the proposed method reduces the peak value of common-mode voltage (CMV) to $42 \%$ by using a mediumvalued phase voltage to generate the zero vectors. Simulation results are shown to validate the effectiveness of the proposed PCC method.
\end{abstract}

Keywords: Predictive current control (PCC), matrix converters (MCs), common-mode voltage (CMV).

\section{Introduction}

During the past decades, matrix converters (MCs) have become an attractive converter to alternate the back-to-back converter due to its superior advantages such as sinusoidal input/output waveforms, controllable input power factor, bidirectional power lfow capability, and a compact power circuit [1], [2]. Amon $\square$ the $\mathrm{MC} \backsim \mathrm{s}$ modulation methods, the predictive current control (PCC) has recently emerged as a feasible and competitive method compared with the classic linear controllers [3], [4].

The PCC method has been successfully applied to control the output current and the reactive power for MCs [5]. This method used a discrete-time model of the load to predict the output current for the 27 switching configurations (SCs) of the MC, and then the vector which minimizes a cost function is applied. In [6], the PCC method has been adopted to reduce the common-mode voltage (CMV), which is one of the main sources of the shaft voltage, leakage current, and bearing current damage. Even though [6] can suppress the RMS value of the MC's CMV without any degradation of the performance of the drive until reaching $40 \%$, it is difficult to choose a proper weighting factor for the cost function. From the previous studies, the PCC methods for MC have demonstrated many advantages such as fast dynamic responses, easy inclusion of nonlinear constraints and no requirement of modulations. However, the PCC method needs a high amount of calculations, which results in long calculation time.

In order to overcome these drawbacks, this paper proposes a simplified PCC method for MCs to reduce the calculation time without affecting the output performance. The proposed method simplifies the current prediction process and reduces the number of the cost function calculation by utilizing the sector distribution. As a result, the calculation time is effectively reduced. In addition, by using the medium-valued phase voltage for zero vector according to input voltage sector distribution, the peak value of CMV is reduced to $42 \%$ without the required weighting factor in the cost function. Simulation results are shown to validate the effectiveness of the proposed PCC method.

\section{Conventional Predictive Current Control}

Fig. 1 shows the power circuit of the MC system. It is composed of nine bidirectional power switches, which connects a three-phase voltage source to a three-phase passive load. The input phases should not be short-circuited, and the load side should never be open circuit. With these constraints, 27 possible SCs are allowed to control the MC. These SCs are categorized into three groups: 1) active vectors, 2) zero vectors and 3) rotating vectors. All 27 possible SCs and their corresponding peak values of the CMV are listed in Table I. 


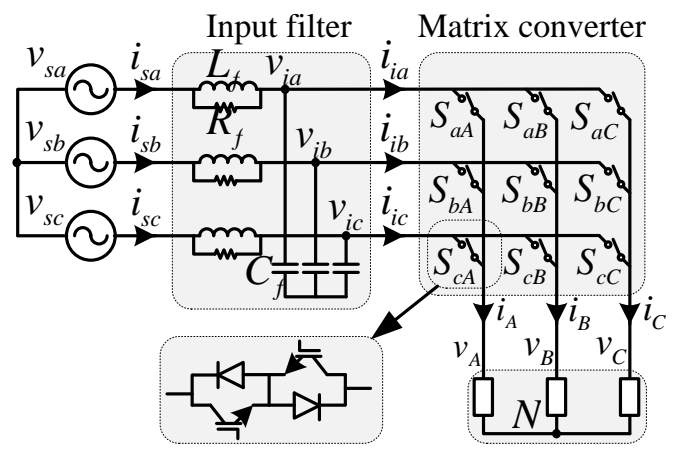

Bidirectional Switch 3-phase RL Load

Fig. 1: Three-phase to three-phase MC.

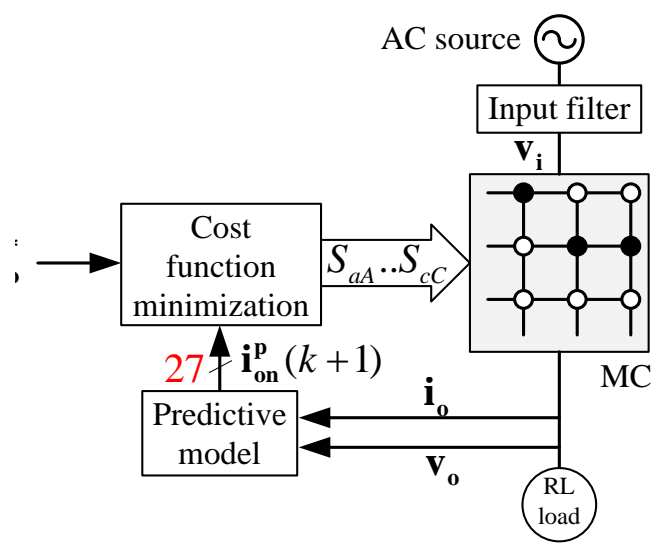

Fig. 2: Block diagram of conventional PCC method.
Table 1: Possible SCs in MC.

\begin{tabular}{|c|c|c|c|c|}
\hline \multirow{2}{*}{ Group } & \multirow{2}{*}{$\frac{\text { SCs }}{\text { No. ABC }}$} & Output Voltage & Input Current & \multirow{2}{*}{$\begin{array}{l}\text { CMV } \\
\text { (peak) }\end{array}$} \\
\hline & & $\begin{array}{cc}\mathrm{v}_{\mathrm{o}} & \alpha_{\mathrm{o}} \\
\end{array}$ & $\mathrm{i}_{\mathrm{i}} \quad \beta_{\mathrm{i}}$ & \\
\hline \multirow{18}{*}{ Group 1} & $+1 \mathrm{abb}$ & $2 v_{a b} / 3$ & $2 \mathrm{i}_{\mathrm{A}} / \sqrt{3}-\pi / 6$ & \multirow{18}{*}{$\mathrm{V}_{\mathrm{i}} / \sqrt{3}$} \\
\hline & -1 baa & $-2 v_{a b} / 3$ & $-2 \mathrm{i}_{\mathrm{A}} / \sqrt{3}-\pi / 6$ & \\
\hline & +2 bcc & $2 \mathrm{v}_{\mathrm{bc}} / 3$ & $2 \mathrm{i}_{\mathrm{A}} / \sqrt{3} \quad \pi / 2$ & \\
\hline & $-2 \mathrm{abb}$ & $-2 v_{b c} / 3$ & $-2 \mathrm{i}_{\mathrm{A}} / \sqrt{3}$ & \\
\hline & $+3 \mathrm{abb}$ & $2 \mathrm{v}_{\mathrm{ca}} / 3$ & $2 \mathrm{i}_{\mathrm{A}} / \sqrt{3}$ & \\
\hline & $-3 a b b$ & $-2 v_{c a} / 3$ & $-2 \mathrm{i}_{\mathrm{A}} / \sqrt{3}$ & \\
\hline & $+4 \mathrm{abb}$ & $2 \mathrm{v}_{\mathrm{ab}} / 3 \quad 2 \pi / 3$ & $2 \mathrm{i}_{\mathrm{B}} / \sqrt{3}$ & \\
\hline & $-4 \mathrm{abb}$ & $-2 v_{a b} / 32 \pi / 3$ & $-2 \mathrm{i}_{\mathrm{B}} / \sqrt{3}$ & \\
\hline & $+5 \mathrm{abb}$ & $2 \mathrm{v}_{\mathrm{bc}} / 3 \quad 2 \pi / 3$ & $2 \mathrm{i}_{\mathrm{B}} / \sqrt{3}$ & \\
\hline & $-5 a b b$ & $-2 v_{b c} / 32 \pi / 3$ & $-2 \mathrm{i}_{\mathrm{B}} / \sqrt{3}$ & \\
\hline & $+6 \mathrm{abb}$ & $2 \mathrm{v}_{\mathrm{ca}} / 3 \quad 2 \pi / 3$ & $2 \mathrm{i}_{\mathrm{B}} / \sqrt{3}$ & \\
\hline & $-6 a b b$ & $-2 v_{\mathrm{ca}} / 3 \quad 2 \pi / 3$ & $-2 \mathrm{i}_{\mathrm{B}} / \sqrt{3}$ & \\
\hline & $+7 \mathrm{abb}$ & $2 v_{a b} / 3 \quad 4 \pi / 3$ & $2 \mathrm{i}_{\mathrm{C}} / \sqrt{3}-\pi / 6$ & \\
\hline & $-7 \mathrm{abb}$ & $-2 v_{a b} / 3 \quad 4 \pi / 3$ & $-2 \mathrm{i}_{\mathrm{C}} / \sqrt{3}$ & \\
\hline & $+8 \mathrm{abb}$ & $2 v_{b c} / 3 \quad 4 \pi / 3$ & $2 \mathrm{i}_{\mathrm{C}} / \sqrt{3}$ & \\
\hline & $-8 \mathrm{abb}$ & $-2 v_{b c} / 3 \quad 4 \pi / 3$ & $-2 \mathrm{i}_{\mathrm{C}} / \sqrt{3}$ & \\
\hline & $+9 \mathrm{abb}$ & $2 \mathrm{v}_{\mathrm{ca}} / 3 \quad 4 \pi / 3$ & $2 \mathrm{i}_{\mathrm{C}} / \sqrt{3}$ & \\
\hline & $-9 \mathrm{abb}$ & $-2 v_{\mathrm{ca}} / 3 \quad 4 \pi / 3$ & $-2 \mathrm{i}_{\mathrm{C}} / \sqrt{3}$ & \\
\hline \multirow{3}{*}{ Group 2} & $0_{\mathrm{a}}$ ааа & 0 & $\mathrm{X}$ & \multirow{3}{*}{$\mathrm{V}_{\mathrm{i}}$} \\
\hline & $0_{\mathrm{b}} \mathrm{bbb}$ & 0 & $\mathrm{x}$ & \\
\hline & $0_{\mathrm{c}} \quad \mathrm{ccc}$ & $\mathrm{x}$ & $\mathrm{x}$ & \\
\hline \multirow{6}{*}{ Group 3} & $r_{1} \quad a b c$ & $\alpha_{i}$ & $\beta_{\mathrm{o}}$ & \multirow{6}{*}{0} \\
\hline & $\mathrm{r}_{2} \mathrm{acb}$ & $-\alpha_{\mathrm{i}}$ & $-\beta_{\mathrm{o}}$ & \\
\hline & $\mathrm{r}_{3} \mathrm{cab}$ & $\mathrm{V}_{\mathrm{i}} \quad 2 \pi / 3+\alpha_{\mathrm{i}}$ & $\mathrm{I}_{\mathrm{o}}-2 \pi / 3+\beta_{\mathrm{o}}$ & \\
\hline & $\mathrm{r}_{4}$ bac & $\mathrm{V}_{\mathrm{i}} \quad 2 \pi / 3-\alpha_{\mathrm{i}}$ & $\mathrm{I}_{\mathrm{o}} \quad 2 \pi / 3-\beta_{\mathrm{o}}$ & \\
\hline & $\mathrm{r}_{5} \mathrm{bca}$ & $V_{i}-2 \pi / 3+\alpha_{i}$ & $\mathrm{I}_{\mathrm{o}} \quad 2 \pi / 3+\beta_{\mathrm{o}}$ & \\
\hline & $\mathrm{r}_{6} \mathrm{cba}$ & $V_{i}-2 \pi / 3-\alpha_{i}$ & $\mathrm{I}_{\mathrm{o}}-2 \pi / 3-\beta_{\mathrm{o}}$ & \\
\hline
\end{tabular}

In this paper, the three-phase variables are characterized by means of space vector. With the relevant symbols shown in Fig.1, the input voltage space vector $\mathbf{v}_{\mathbf{i}}$ is defined as following:

$$
\mathbf{v}_{\mathbf{i}}=2\left(v_{i a}+v_{i b} e^{j 2 \pi / 3}+v_{i c} e^{j 4 \pi / 3}\right) / 3=V_{i} e^{j \alpha_{i}} .
$$

A similar definition can be applied to obtain the output voltage, input and output current vectors, i.e., $\mathbf{v}_{\mathbf{o}}$, $\mathbf{i}_{\mathbf{i}}$ and $\mathbf{i}_{\mathbf{o}}$, respectively.

The PCC method uses a model of the system to predict the future behavior of the controlled variables. The dynamic model of the passive load is defined as following:

$$
\mathbf{v}_{\mathbf{o}}=R_{l} \mathbf{i}_{\mathbf{o}}+L_{l} \frac{d \mathbf{i}_{\mathbf{o}}}{d t}
$$

where $R_{l}$ and $L_{l}$ are the load resistance and inductance, respectively. Using the forward Euler discretization for (2) with a sampling period $T_{s}$, the 27 predicted load currents $\mathbf{i}_{\mathbf{o n}}^{\mathbf{p}}(k+1)$ corresponding to the 27 output voltage vectors $\mathbf{v}_{\mathbf{o n}}(k+1)$ of the MC can be expressed as the following equation:

$$
\mathbf{i}_{\mathbf{o n}}^{\mathbf{p}}(k+1)=\frac{T_{s}}{R_{l} T_{s}+L_{l}}\left\lfloor\frac{L_{l}}{T_{s}} \mathbf{i}_{\mathbf{o}}(k)+\mathbf{v}_{\mathbf{o n}}(k+1)\right\rfloor, \quad(n=1 \sim 27) .
$$


As the control target is to regulate the load current, the cost function for the load current can be given as following:

$$
g_{n}(k+1)=\left|\mathbf{i}_{\mathbf{o}}^{*}(k+1)-\mathbf{i}_{\mathbf{o n}}^{\mathbf{p}}(k+1)\right|^{2},(n=1 \sim 27) .
$$

The block diagram of the conventional PCC method for MCs is shown in Fig. 2. This control scheme requires 27 times calculation to obtain the predictive current as well as 27 times calculation to find the cost function to find optimal SC. So, it takes a long computing time.

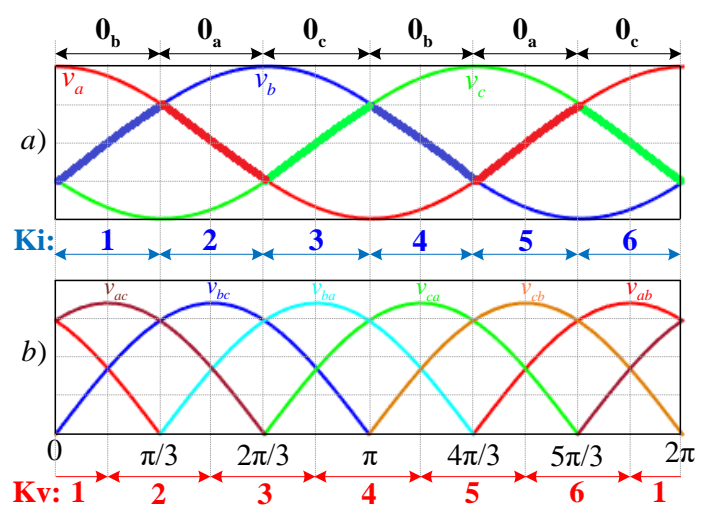

Fig. 3: (a) Input voltage and (b) Required output voltage sector determination.

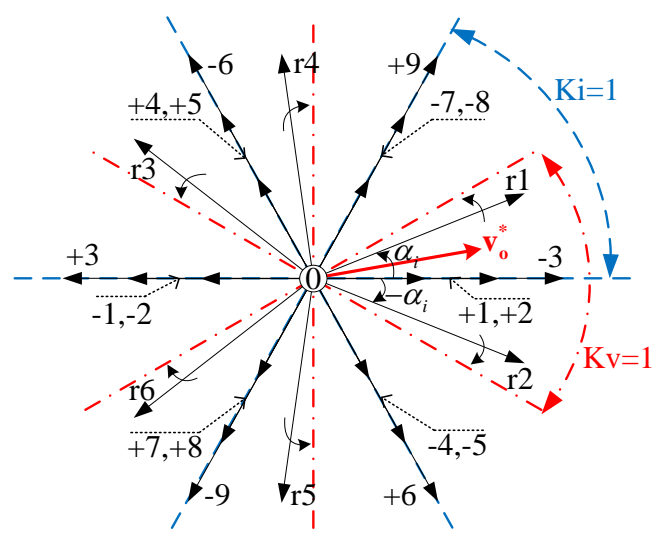

Fig. 4: Sector distribution of voltage vectors for selection of simplified PCC method when $K_{i}=1$ and $K_{v}=1$.

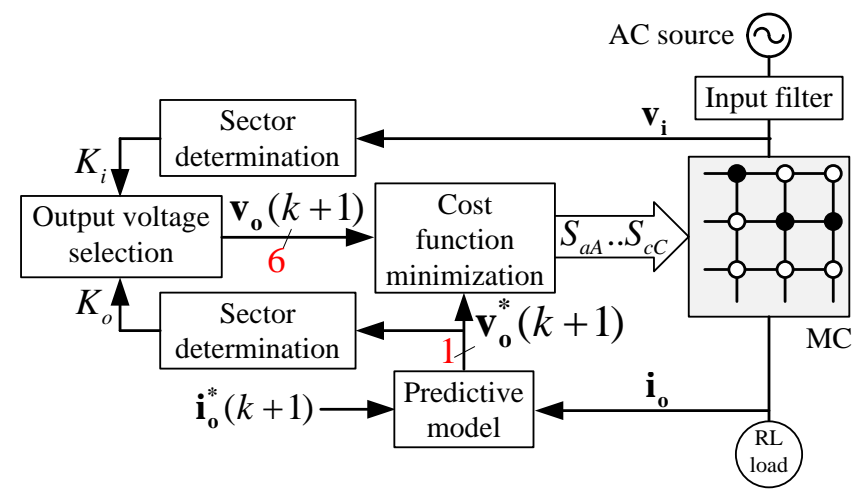

Fig. 5: Block diagram of simplified PCC method. 
Table 2: Novel Look-up Table for Simplified PCC of MC.

\begin{tabular}{|l|c|c|c|}
\hline \multicolumn{1}{|r|}{$\mathrm{K}_{\mathrm{i}}$} & $\underline{1}$ or 4 & $\underline{2}$ or 5 & $\underline{3}$ or 6 \\
\hline$\underline{1}$ or 4 & $+1,+2,-3, \mathrm{r}_{2}, \mathrm{r}_{1}, 0_{\mathrm{b}}$ & $-1,+2,-3, \mathrm{r}_{5}, \mathrm{r}_{4}, 0_{\mathrm{a}}$ & $-1,+2,+3, \mathrm{r}_{4}, \mathrm{r}_{5}, 0_{\mathrm{c}}$ \\
\hline$\underline{2}$ or 5 & $-7,-8,+9, \mathrm{r}_{1}, \mathrm{r}_{4}, 0_{\mathrm{b}}$ & $+7,-8,+9, \mathrm{r}_{4}, \mathrm{r}_{1}, 0_{\mathrm{a}}$ & $+7,-8,-9, \mathrm{r}_{5}, \mathrm{r}_{6}, 0_{\mathrm{c}}$ \\
\hline$\underline{3}$ or 6 & $+4,+5,-6, \mathrm{r}_{4}, \mathrm{r}_{3}, 0_{\mathrm{b}}$ & $-4,+5,-6, \mathrm{r}_{1}, \mathrm{r}_{6}, 0_{\mathrm{a}}$ & $-4,+5,+6, \mathrm{r}_{6}, \mathrm{r}_{1}, 0_{\mathrm{c}}$ \\
\hline$\underline{4}$ or 1 & $-1,-2,+3, \mathrm{r}_{3}, \mathrm{r}_{6}, 0_{\mathrm{b}}$ & $+1,-2,+3, \mathrm{r}_{6}, \mathrm{r}_{3}, 0_{\mathrm{a}}$ & $+1,-2,-3, \mathrm{r}_{1}, \mathrm{r}_{2}, 0_{\mathrm{c}}$ \\
\hline$\underline{5}$ or 2 & $+7,+8,-9, \mathrm{r}_{6}, \mathrm{r}_{5}, 0_{\mathrm{b}}$ & $-7,+8,-9, \mathrm{r}_{3}, \mathrm{r}_{2}, 0_{\mathrm{a}}$ & $-7,+8,+9, \mathrm{r}_{2}, \mathrm{r}_{3}, 0_{\mathrm{c}}$ \\
\hline$\underline{6}$ or 3 & $-4,-5,+6, \mathrm{r}_{5}, \mathrm{r}_{2}, 0_{\mathrm{b}}$ & $+4,-5,+6, \mathrm{r}_{2}, \mathrm{r}_{5}, 0_{\mathrm{a}}$ & $+4,-5,-6, \mathrm{r}_{3}, \mathrm{r}_{4}, 0_{\mathrm{c}}$ \\
\hline
\end{tabular}

\section{Simplified Predictive Current Control}

The proposed method can reduce the amount of calculations by using the "required output voltage vector (ROV)" $\mathbf{v}_{\mathbf{o}}^{*}(k+1)$ for the prediction process instead of the predictive current calculation. The voltage vector $\mathbf{v}_{\mathbf{o}}^{*}(k+1)$ that makes the predictive current $\mathbf{i}_{\mathbf{o n}}^{\mathbf{p}}(k+1)$ close to its reference $\mathbf{i}_{\mathbf{o}}^{*}(k+1)$ can be determined from $(3)$ by replacing $\mathbf{i}_{\mathbf{o n}}^{\mathbf{p}}(k+1)$ with $\mathbf{i}_{\mathbf{o}}^{*}(k+1)$ :

$$
\mathbf{v}_{\mathbf{o}}^{*}(k+1)=\left(R_{l}+\frac{L_{l}}{T_{s}}\right) \mathbf{i}_{\mathbf{o}}^{*}(k+1)-\frac{L_{l}}{T_{s}} \mathbf{i}_{\mathbf{o}}(k) .
$$

The control loop of the simplified PCC method selects one suitable output voltage vector, which is closest to the ROV in (5). The new cost function is defined as following:

$$
g_{n}^{\prime}(k+1)=\left|\mathbf{v}_{\mathbf{o}}^{*}(k+1)-\mathbf{v}_{\mathbf{o n}}(k+1)\right|^{2},(n=1 \sim 27) \text {. }
$$

In order to reduce the number of the cost function calculation, the sector distribution of the input voltage and the ROV is considered. The sector of the input voltage vector $\left(K_{i}\right)$ and the ROV $\left(K_{v}\right)$ are defined as shown in Fig. 3. For easy explanation, both $\mathbf{v}_{\mathbf{i}}$ and $\mathbf{v}_{\mathbf{o}}^{*}(k+1)$ are assumed to lie in sector 1 without missing the generality of the analysis. Fig. 4 shows all 27 output voltage space vectors when $K_{i}=1$ and $K_{v}=1$. A geometrical analysis shows that when $\mathbf{v}_{\mathbf{o}}^{*}(k+1)$ is located in sector $1\left(K_{v}=1\right)$, the candidate vectors to be the closest vector can be six vectors: three active vector $+1,+2,-3$, two rotating vector $\mathrm{r}_{1}, \mathrm{r}_{2}$ and one zero vector. The proper zero vector is selected by taking into account the CMV according to the input voltage magnitude. Among the zero vectors in Group 2 in Table I, we select the zero vector which is generated by the minimum magnitude input phase voltage. For example, when the input voltage vector is located in section I, the zero vector $\mathbf{0}_{\mathrm{b}}$ is used as shown in Fig. 3(a). Table II summarizes the selected candidate vectors for any combination of the input voltage and the ROV.

Fig. 5 shows the block diagram of the simplified PCC method for MCs. The amounts of calculations are significantly reduced by using the ROV and its sector distribution; the number of calculation to find the variables such as the predictive current, the ROV and its cost function is reduced from 54 to 7. 

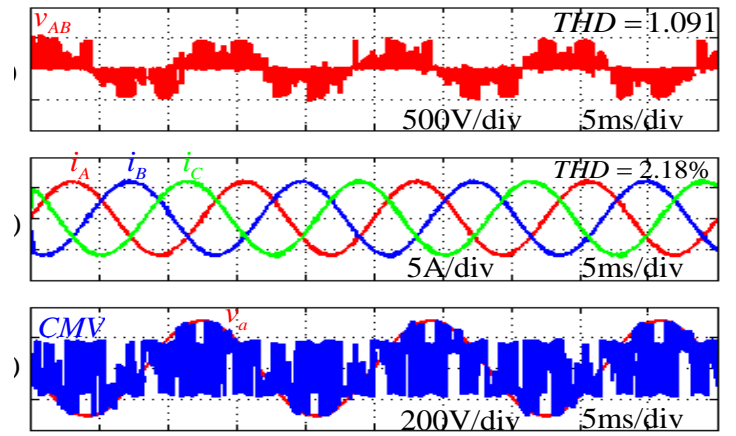

Fig. 6: (a) Output line-to-line voltage, (b) Output current, (c) CMV and input phase voltage with the conventional PCC.
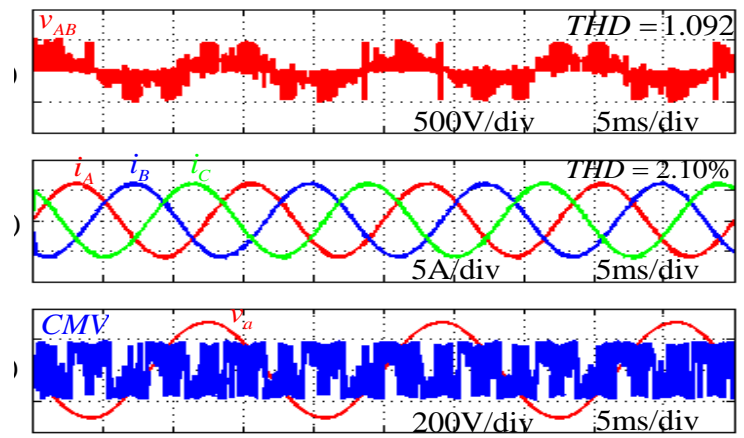

Fig. 7: (a) Output line-to-line voltage, (b) Output current, (c) CMV and input phase voltage with the proposed PCC.

\section{Simulation Results}

In order to evaluate the performance of the proposed PCC method, the simulation is carried out by using MATLABSimulink software. The parameters used for simulation are: three-phase source power $220 \mathrm{~V} / 60 \mathrm{~Hz}$; balanced three-phase load $R_{l}=15 \Omega, L_{l}=10 \mathrm{mH}$; input filter with $L_{f}=1.4 \mathrm{mH}, C_{f}=22 \mu \mathrm{C}, R_{f}=30 \Omega$, and the sampling frequency $f_{s}=50 \mathrm{kHz}$.

Figs. 6 and 7 show the output performances of the conventional PCC method and the proposed PCC method, respectively, in case of the reference output current magnitude $I_{o}=6 \mathrm{~A}$ with the frequency $f_{o}=80 \mathrm{~Hz}$. Comparing Fig. 6 with 7, the THDs of the output voltage and current with the proposed PCC method maintain almost same as those with the conventional PCC method. However, the CMV with the proposed PCC method is reduced compared to that with the conventional PCC; the maximum CMV value reaches $\pm 311 \mathrm{~V}$ with the conventional PCC method, and the proposed method reduces the maximum CMV value to $\pm 179 \mathrm{~V}$, which is $42 \%( \pm 1 / \sqrt{3})$ of the peak value of the input phase voltage.

\section{Conclusions}

This paper has presented a simplified PCC method to reduce the high amount of calculation for MCs. The proposed method makes the current prediction process simple by using the required output voltage vector. Furthermore, the number of the cost function calculation is also significantly reduced by utilizing the sector distribution. Additionally, a very effective zero vector selector has been developed to minimize the peak value of the CMV. In spite of the simplified PCC algorithm, the performance of the proposed PCC method is not degraded and the CMV is reduced to $42 \%$ compared to that of the conventional method. The effectiveness of the proposed method is verified by simulation results.

\section{Acknowledgements}

This work was partly supported by the National Research Foundation of Korea Grant funded by the Korean Government (NRF-2015R1D1A1A09058166) and the Network-based Automation Research Center (NARC) funded by the Ministry of Trade, Industry \& Energy.

\section{References}

[1] P. Wheeler, J. Rodriguez, J. Clare, L. Empringham, and A. Weinstein, "Matrix converters: A technology review," IEEE Trans. Ind. Electron., vol. 49, no. 2, pp. 276-288, 2002.

[2] H. M. Nguyen, H. H. Lee, and T. W. Chun, "Input Power Factor Compensation Algorithms Using a New Direct-SVM Method for Matrix Converter," IEEE Trans. Ind. Electron., vol. 58, no. 1, pp. 232-243, 2011.

[3] J. Rodriguez, M. Rivera, J. W. Kolar, and P. W. Wheeler, "A Review of Control and Modulation Methods for Matrix Converters," IEEE Trans. Ind. Electron., vol. 59, no. 1, pp. 58-70, 2012.

[4] M. Rivera, et al., "A comparative assessment of model predictive current control and space vector modulation in a direct matrix converter," IEEE Trans. Ind. Electron., vol. 60, no. 2, pp. 578-588, 2013.

[5] R. Vargas, J. Rodríguez, U. Ammann, and P. Wheeler, "Predictive Current Control of an Induction Machine Fed by a Matrix Converter With Reactive Power Control," IEEE Trans. Ind. Electron., vol. 55, pp. 4362 - 4371, 2008.

[6] R. Vargas, U. Ammann, J. Rodríguez, and J. Pontt, "Predictive Strategy to Control Common-Mode Voltage in Loads Fed by Matrix Converters," IEEE Trans. Ind. Electron., vol. 55, no. 12, pp. 4372 - 4380, 2008. 